noted that leucocyte ascorbic acid levels might be low in pa ients with steatorrhoea, but did not give figures or details of the dietary intake of vitami $>$ C. The diet histories of the patients show a mean intake of ascorbic acid of the order of $40 \mathrm{mg}$. daily, which is above the level recommended by the B.M.A. (1950). It is noteworthy that the mean leucocyte ascorbic acid level in the control group (mean age 54.9 years) is $20.8 \mu \mathrm{g} . / 10^{8}$ W.B.C. Bowers and Kubik (19t5) observed that the leucocyte ascorbic acid levels in elderly patients living at home (mean age 76.2 years) were lower than in a group of patients of working age. Andrews and Brook (1966) have confirmed that low leucocyte ascorbic acid levels are encountered in the elderly, but they suggest that this is possibly due to poor dietary intake of ascorbic acid, and point out that the low leucocyte ascorbic acid levels of old people can, by giving oral ascorbic acid, be raised quickly to levels comparable to those found in younger people. The available diet histories in the present control group indicate a satisfactory intake of ascorbic acid.

The most likely cause of the low levels of leucocyte ascorbic acid is malabsorption of this water-soluble vitamin, but there may be an increased demand for ascorbic acid. Phenolic acids are present in excess in the urine of patients with steatorrhoea, and Boscott and Cooke (1954) suggested that there is an abnormal demand for ascorbic acid for their detoxification. In addition, one specific action of ascorbic acid is its ability to protect an enzyme, $p$-hydroxyphenyl pyruvic acid oxidase, from its substrate, a phenolic acid (Goodman and Gilman, 1965). These mechanisms may partly account for the low leucocyte ascorbic acid levels in the patients of the present series.

Only five of the 26 patients investigated showed, in fact, clinical evidence of vitamin-C deficiency. The significance of subclinical ascorbic acid deficiency is not yet certain, though there is a significant correlation between low levels of leucocyte ascorbic acid and sublingual petechiae (Andrews and Brook, 1966), and also between such levels and a high incidence of wound dehiscence in surgical patients (Crandon et al., 1961).

It is known that vitamin-C deficiency occurs more commonly in the elderly (Bowers and Kubik, 1965) and in those subsisting on poor diets, whether by reason of food faddism or apathy or poverty. It would seem from the present series that patients who have intestinal malabsorption or who have had gastric surgery should be added to those groups in whom ascorbic-acid deficiency may be more readily suspected. In states of malabsorption or after gastric surgery the leucocyte ascorbic acid should therefore be routinely measured, and, where low, oral vitamin-C supplements should be given. If such a test is not possible it would seem reasonable to give routine oral vitamin C to all patients, especially elderly ones.

\section{Summary}

Twenty-six patients who either had intestinal malabsorption or had undergone gastric surgery had significantly lower "leucocyte ascorbic acid" levels than 26 control subjects. The mean leucocyte ascorbic acid level in the controls was $20.8 \mu \mathrm{g} . / 10^{2}$ W.B.C. and in the patients $11.7 \mu \mathrm{g} . / 10^{8}$ W.B.C. $(\mathrm{P}<0.01)$.

Five of the 26 patients had clinical evidence of increased capillary fragility and three had purpura.

The estimated dietary intake of vitamin $C$ in all these patients was within the accepted normal limits.

It is suggested that patients with intestinal malabsorption and those who have been subjected to gastric surgery, especially if they are elderly, should have their diet supplemented with vitamin C. If leucocyte ascorbic acid levels can be measured, and are found to be low, the administration of ascorbic acid would seem to be obligatory.

We are indebted to Dr. E. B. Hendry, Biochemistry Department, Western Infirmary, Glasgow, in whose department the "leucocyte ascorbic acid" levels were estimated; to Dr. H. E. Hutchinson, Haematology Department, Western Infirmary, Glasgow, for platelet counts and serum folate estimations ; and to Miss C. Leahy, chiet dietitian, Western Infirmary, Glasgow, for the diet histories.

\section{REFERENCES}

Andrews, J., and Brook, M. (1966). Lancet, 1, 1350.

Badenoch, J. (1960). Brit. med. 7., 2, 879.

Bartley, W., Krebs, H A., and O'Brien, J. R. P. (1953). Spec. Rep. Sor. med. Res. Coun. (Lond.), No. 280

Boscott, R. J., and Cooke, W. T. (1954). Quart. F. Med., 23, 307.

Bowers, E. F., and Kubik, M. M. (1965). Brit. F. clin. Pract., $19,141$. British Medical Association (1950). Report of the Commitlee on Nutrition. London.

Crandon, J. H., Lennihan, R., jun., Mikal, S., and Reif, A. E. (1961)

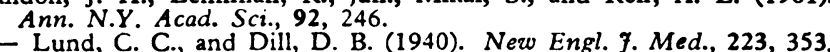

Denson, K. W., and Bowers, E. F. (1961). Clin. Sci., 21, 157 .

Denson, K. W., and Bowlers, E. F. (1961). The Pharmacological Basis of Goodman, L. S., and Gilman, A. (1965)

Harrison, G. A. (1947). Chemical Methods in Clinical Medicine, 3rd ed. p. 490. London.

McCance, R. A., and Widdowson, E. M. (1960). Spec. Rep. Ser. med. Res. Coun. (Lond.), No. 297.

Roe, J. H., and Rice, E. W. (1948). 7. biol. Chem., 173, 507.

Spray, G. H. (1964). 7. clin. Path., 17, 660.

Stewart, S. and Booth, C. C. (1964). Clin. Sct., 27, 15.

Varley, H. (1962). Practical Clinical Biochemistry, 3rd ed., p. 356 London.

\title{
Plasma Cortisol Levels in Heart Failure
}

\author{
C. K. CONNOLLY,* M.A., M.B., M.R.C.P. ; M. R. WILLS,* M.D., M.C.PATH.
}

Brit. med. 9., 1967, 2, 25-27

Cushing's syndrome is generally agreed to be the result of an excessive endogenous secretion of cortisol (Longson and Christy, 1964). Therefore the definitive test in the diagnosis of Cushing's syndrome is the determination of the cortisol secretion rate. The methods available for the determination of that rate are too complex for routine use. The diagnosis of Cushing's syndrome is therefore made, indirectly, by measurement of the concentration of cortisol and its metabolites in blood and urine (Ross, Marshall-Jones, and Friedman, 1966). In normal subjects there is a circadian rhythm of the concentration of cortisol in blood with the minimum value about midnight and maximum value

\footnotetext{
- From the Departments of Medicine and Chemical Pathology, Royal
} Free Hospital, London W.C.1. between 06.00 and 09.00 hours (Mills, 1966). In Cushing's syndrome there is abolition of the cortisol circadian rhythm due to elevation of the midnight level (Doe, Vennes, and Flink, 1960 ; Ekman, Håkansson, McCarthy, Lehmann, and Sjögren, 1961). Ross et al. (1966) reported that this occurred in eight out of nine patients with Cushing's syndrome and stated that " absence of a diurnal rhythm is very helpful in diagnosis."

Congestive cardiac failure may occur in patients who have many of the clinical features of Cushing's syndrome. We have recently found raised plasma cortisol levels at midnight in patients with congestive cardiac failure. This investigation was started after we had found a high midnight plasma cortisol level in a patient with congestive cardiac failure who had some 
of the clinical features of Cushing's syndrome. We report preliminary findings and clinical details of six patients so far studied.

\section{Methods}

Plasma cortisol concentration was estimated with a minor modification of a fluorimetric method for free 11-hydroxycorticoids (Mattingly, 1962). This method measures both cortisol and corticosterone. In 75 normal subjects and patients with no evidence of endocrine disturbances the plasma cortisol range was 1-9 $\mu \mathrm{g} . / 100 \mathrm{ml}$. at midnight and $7-25 \mu \mathrm{g} . / 100 \mathrm{ml}$. at 09.00 hours, showing an increase of at least $75 \%$ on the midnight level.

\section{Results}

The results obtained on the patients studied are shown in the Table. No patient was studied on the first night of hospital admission. Case 1 was the original patient in congestive cardiac failure due to ischaemic heart disease, who had a history of hypertension (B.P. 200/120), obesity, and abnormal glucose tolerance. The raised cortisol levels were not completely suppressed by oral dexamethasone $8 \mathrm{mg}$./day for two days, while she was still in cardiac failure. During a recent admission for diverticulitis, and while no longer in cardiac failure, normal plasma cortisol levels were obtained-9 $\mu \mathrm{g} . / 100 \mathrm{ml}$. at midnight and $19 \mu \mathrm{g} . / 100 \mathrm{ml}$. at 09.00 hours.

Cases 2 and 3 had congestive cardiac failure due to ischaemic heart disease ; they both responded well to treatment, and the increased plasma cortisol concentrations returned to normal when the cardiac failure had resolved. Case 4 was a patient with both cardiac and renal failure. The cardiac failure followed myocardial infarction, which precipitated failure of kidneys already severely damaged by chronic obstruction of the urinary tract. This patient was the only one in the group who was seriously ill. The renal failure persisted throughout the period of observation and was the cause of his subsequent death. The raised plasma cortisol levels returned to normal when the cardiac failure was relieved, though there had been no improvement in renal function.

Case 5 presented one year ago in cardiac failure with hypertension (B.P. 240/110), obesity, and abnormal glucose-tolerance curve. A diagnosis of Cushing's syndrome was made on the clinical findings and the in tial plasma cortisol levels. Because she remained in cardiac failure she was regarded as unfit for surgical exploration of her adrenals. Ten months ago she was given a therapeutic course of pituitary irradiation, but the midnight plasma cortisol levels have remained high, with values in the range of $16-21 \mu \mathrm{g} . / 100 \mathrm{ml}$. Though Cushing's syndrome cannot be excluded in this patient with chronic cardiac failure, we feel the diagnosis must now be questioned. Case 6 was in left ventricular failure with uncontrolled atrial fibrillation, almost certainly due to thyrotoxicosis. At the time of the first plasma cortisol estimations she was agitated, and normal levels were later obtained, when the only change in her condition was the disappearance of the left ventricular failure. She was the only patient who did not have oedema. It is also of interest to note that though the midnight cortisol level was raised she was the only patient who maintained a circadian rhythm by a proportionately raised level at 09.00 hours.

We have found raised midnight cortisol levels in two further patients in whom, there was not a clear-cut diagnosis of congestive cardiac failure. In a woman aged 68 with occasional oedema, pulmonary congestion, and recurrent cardiac ischaemia without frank infarction levels of cortisol were $16 \mu \mathrm{g} . / 100 \mathrm{ml}$. at both midnight and 09.00 hours. In a man aged 70 with breathlessness and lung shadowing, probably related to ischaemic heart disease and acute on chronic bronchitis, plasma cortisol levels of 22 and $21 \mu \mathrm{g} . / 100 \mathrm{ml}$. were obtained at midnight and 09.00 hours respectively.

\section{Discussion}

The normal circadian rhythm of plasma cortisol secretion is due to a rhythmic variation in the plasma A.C.T.H. concentration following a " biological clock" (Mills, 1966). Autonomous activity of either the adrenal or the pituitary, as in Cushing's syndrome, causes obliteration of the cortisol rhythm. A.C.T.H. secretion is also controlled by a "feed-back" system which depends on the level of free cortisol in the plasma.

Cortisol in plasma is cleared by conjugation in the liver, and in patients with cirrhosis the rate of clearance of injected cortisol is appreciably slower than in normal subjects (Brown, Willardson, Samuels, and Tyler, 1954 ; Englert, Brown, Wallach, and Simons, 1957 ; Jenkins, 1961). Plasma-free cortisol levels in cirrhotic patients have been previously reported as normal (Brown et al., 1954 ; Klein, Papadatos, Fortunato, Byers, and Puntereri, 1955; Peterson, 1960) with low levels of the conjugated fraction (Klein et al., 1955). Recently, however, Tucci, Albacete, and Martin (1966) reported abolition of the plasma cortisol rhythm in patients with cirrhosis, with high levels of both conjugated and unconjugated fractions in the night specimens. These latter results showed a similar pattern to those in patients that we have studied with congestive cardiac failure.

A diminution in the rate of blood flow through the liver causes a reduction in the clearance of cortisol from plasma (Englert, Nelson, Brown, Nielsen, and Chou, 1960). In renal damage there is also a reduction in the rate of cortisol clearance (Englert, Brown, Willardson, Wallach, and Simons, 1958), though in terminal patients a failure of hepatic conjugation rather than renal clearance is probably responsible for the loss of diurnal rhythm (Sandberg, Elk-Nes, Migeon, and Samuels, 1956). We think it unlikely that failure of clearance of cortisol by either the liver or the kidney accounts for the loss of the diurnal rhythm in our patients. Disturbance of liver function is small even in gross cardiac cirrhosis. Our patient with renal failure showed a return to the normal cortisol levels despite

Table of Results

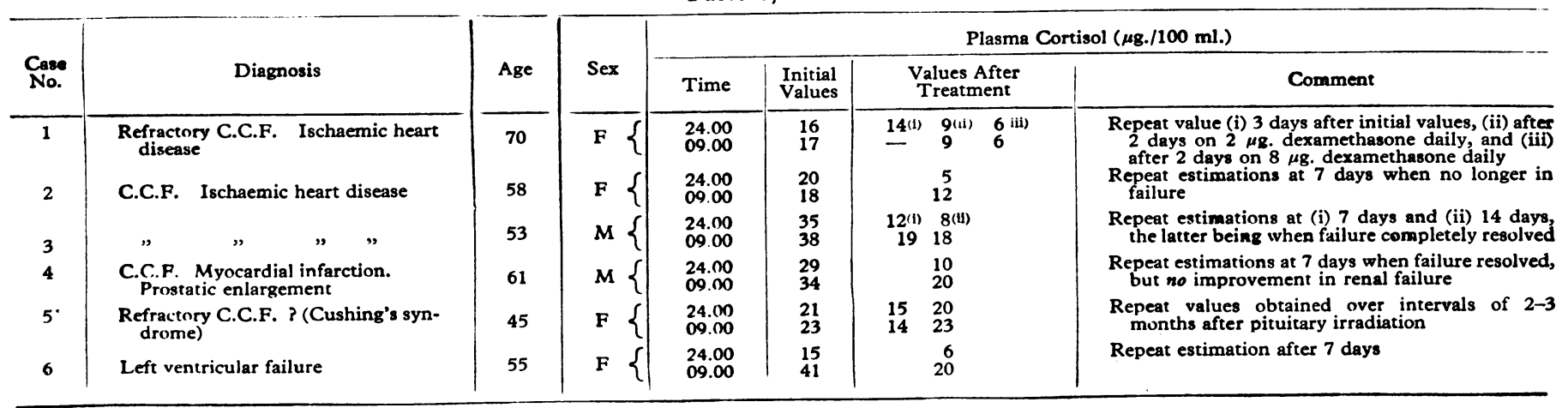


the persistence of a renal disturbance far greater than that usually seen in cardiac failure.

The simplest explanation of our findings is that they are a nonspecific stress response, but we have found normal results in patients equally ill from other causes. Espiner (1966), in a study of patients with " medical stress," found raised urinary cortisol excretion accompanied by an increase in the plasma levels, particularly early in the stress period. One of his patients who also was in cardiac failure had plasma cortisol levels similar to those of our patients. We have observed our patients after the first day of admission and seen abnormalities in plasma cortisol levels throughout an episode of cardiac failure. One patient (Case 1) did not show normal suppression with dexainethasone. These results suggest that there might be an alternative mechanism, possibly outside the pituitary-adrenal axis. This might be related to the known abolition of the circadian rhythm of urinary water and electrolyte excretion in congestive cardiac failure (Brod and Fejfar, 1950 ; Baldwin, Sirota, and Villarreal, 1950; Goldman and Luchsinger, 1956) the mechanism of which is not yet fully elucidated.

Some patients with cardiac failure have secondary aldosteronism. Haemodynamic changes induce a rise in reninangiotension production, which is largely, if not entirely, responsible for increased aldosterone secretion (Conn, Cohen, and Rovner, 1964). The method used in this study estimates both cortisol and corticosterone. Bledsoe, Island, and Liddle (1966) reported that sodium depletion caused an increased production of aldosterone precursors in subjects maintained on dexamethasone. Secretion of corticosterone, which occurs in the aldosterone metabolic pathway, was increased, while cortisol secretion was unaffected. Thus the possibility that we are observing an increase in corticosterone levels rather than cortisol must be considered.

In the only previous study of cortisol levels in heart failure that we were able to find the authors reported high plasma levels at an unstated time in the evening, with normal morning levels (Pekkarinen, Iisalo, Kasanen, Laihinen, and Thomasson, 1960). They did not report such a complete return to normal as we have seen, nor did they report failure to suppress cortisol secretion with dexamethasone.

Further investigations are being carried out in an attempt to elucidate our findings and if possible to correlate them with the disturbance in the electrolyte and water excretion. We report them at this preliminary stage because we feel that the diagnosis of Cushing's syndrome, based on plasma cortisol levels, in patient's with concomitant congestive cardiac failure should be made with caution.

\section{Summary}

Abolition of the circadian rhythm in plasma cortisol levels, with elevation of the midnight values, is reported in five patients with congestive cardiac failure. The disturbance in rhythm persisted throughout an episode of failure and appears to be $\overline{0}$ unrelated to other nonspecific stress mechanisms. The possible $\bar{\sigma}$ mechanisms causing these disturbances are discussed. These findings are of importance in the differential diagnosis of $\mathbb{D}$ Cushing's syndrome, based on plasma cortisol levels where there is concomitant congestive cardiac failure.

\section{RBFERENCES}

Baldwin, D. S., Sirota, J. H., and Villarreal, H. (1950). Proc. Soc. exp. Biol. (N.Y.), 74, 578 .

Bledsoe, T., Island, D. P., and Liddle, G. W. (1966). F. clin. Invest., $45,524$.

Brod, J., and Feifar, Z. (1950). Quart. F. Med., 19, 187.

Brown, H., Willardson, D. G., Samuels, L. T., and Tyler, F. H. (1954). 7. clin. Invest., 33, 1524.

Conn, J. W., Cohen, E. L., and Rovner, D. R. (1964). f. Amer. med. Ass., $190,213$.

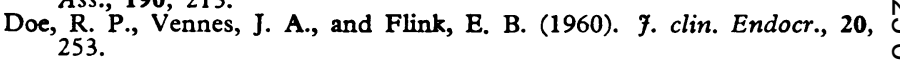

Ekman, H., Håkansson, B., McCarthy, J. D., Lehmann, J., and Sjögren, B. (1961). Ibid., 21, 684

Englert, E., Brown, H., Wallach, S., and Simons, E. L. (1957). Ibid., I 17, 1395. Willardson, D. G., Wallach, S., and Simons, E. L. (1958). Ibid., 18, 36

Nelson, R. M., Brown, H., Nielsen, T. W., and Chou, S. N. (1960). Surgery, 47, 982 .

Espiner, E. A (i9k6). F. Rndocr., 35, 29.

Goldman, R., and Luchsinger, E. B. (1956). 7. clin. Endocr., 16, 28.

Jenkins, J. S. (1961). In The Adrenal Cortex, edited by G. K. McGowan and $M$. Sandler. London.

Klein, R., Papadatos, C., Fortunato, J., Byers, C., and Puntereri, A. (1955). 7. clin. Endocr., 15, 943.

Longson, D., and Christy, N. P. (1964). In Biochemical Disorders in Human Disease, edited by R. H. S. Thompson and E. J. King, 2nd Human Disease, London.

Mattingly, D. (1962). y. clin. Path., 15, 374.

Mills, J. N. (1966). Phystol. Rev., 46, 128.

Pekkarinen, A., Iisalo. E., Kasanen, A., Laihinen, A., and Thomasson, B. (1960). Amer. 3. Cardiol., 5, 604

Peterson, R. E. (1960). \%. clin. Invest., 39, 320.

Ross, E J., Marshall-Jones, P., and Friedman, M. (1966). Quart. 7. Med. 35, 149.

Sandberg, A. A., Eik-Nes, K., Migeon, C. J., and Samuels, L. T. (1956) 9. clin. Endocr., 16, 1001 .

Tucci, J. R., Albacete, R. A., and Martin, M. M. (1966). Gastroenterology, 50, 637. .

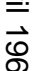

\title{
Circadian Rhythm of Plasma 11-Hydroxycorticosteroids in Depressive Illness, Congestive Heart Failure, and Cushing's Syndrome
}

\author{
M. S. KNAPP,* M.B., M.R.C.P. ; P. M. KEANE, $†$ M.B., M.C.PATH. ; J. G. WRIGHT, $¥$ M.B., CH.B., D.P.M.
}

Brit. med. F., 1967, 2, 27-30

A well-marked circadian rhythm-that is, a rhythm with a periodicity of 24 hours-in the adrenal output of cortisol was first suspected from the pattern of urinary 17-hydroxycorticosteroid excretion (Pincus et al., 1948). This was confirmed by Migeon et al. (1956), who measured plasma levels of 17-hydroxycorticosteroids. Doe et al. (1960) reported the absence of this rhythm in Cushing's syndrome. A study of plasma cortisol, as 17-hydroxycorticosteroid or as free 11hydroxycorticosteroid content, at two or more times in the day has now become a standard investigation in cases of suspected

- Lecturer in Medicine, University of Bristol

$t$ Sentor Registrar in Chemical Pathology. Bristol Royal Infirmary.

¥ Lecturer in Mental Health, University of Bristol.
Cushing's syndrome (Cope, 1965, 1966). A knowledge of the circadian rhythm of 11-hydroxycorticosteroid in other diseases is therefore of increasing importance.

Perkoff et al. (1953) studied 80 patients in an American hospital. They found that the plasma 17-hydroxycorticosteroid rhythm was similar to that of healthy people not in hospital, except in patients with disturbed consciousness or with fever. The only difference was in the level at 04.00 hours. This was usually higher in subjects in hospital and closer to the level at 08.00 hours than to that at 24.00 hours. A possible explanation is the early hour of awakening in American hospitals. These authors did not include patients with psychiatric illness, cardiac failure, or Cushing's syndrome. Pekkarinen et al. (1960) pub-

\section{罱}

\section{烈} . . . . 